\title{
Nelaton catheter assisted versus standard nasogastric tube insertion: a randomized, clinical trial
}

\author{
M. Ghaemi, ${ }^{1}$ N. Mousavinasab ${ }^{2}$ and S. Jalili ${ }^{3}$
}

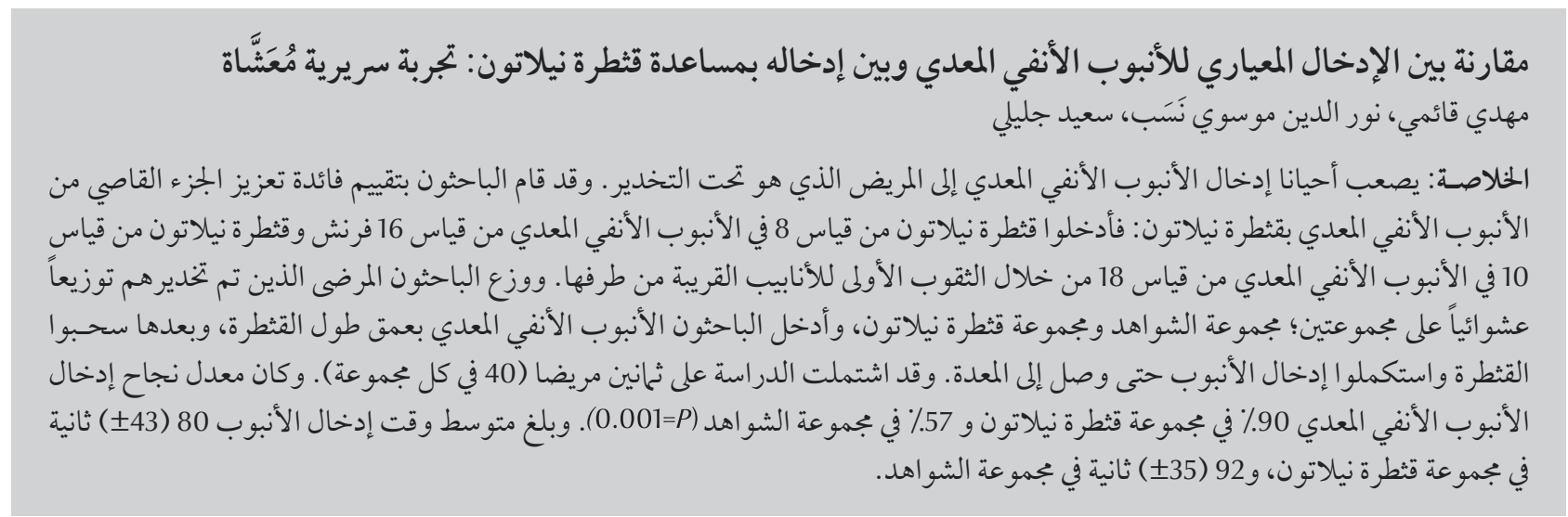

ABSTRACT It is sometimes difficult to insert a nasogastric tube in an anaesthetized patient. We evaluated the benefit of reinforcing the distal portion of the nasogastric tube with a Nelaton catheter: 8 and 10 French Nelaton catheters were inserted into 16 and 18 French nasogastric tubes respectively through the first proximal holes of tubes up to their tips. The patients anaesthetized were randomly allocated into either the control or the Nelaton groups, and nasogastric tube was inserted as deeply as the catheter length, then the catheter was withdrawn and the tube was inserted farther to reach the stomach. Eighty patients (40 in each group) were included in this study. The success rate of nasogastric tube insertion was $90 \%$ in the Nelaton group and $57 \%$ in the control group ( $P=$ 0.001). The mean insertion time was 80 (SD 43) and 92 (SD 35) seconds in the Nelaton and the control groups respectively.

Insertion d'un tube nasogastrique à l'aide d'une sonde Nélaton par rapport à la technique classique : essai clinique randomisé

RÉSUMÉ II est parfois difficile d'insérer un tube nasogastrique sur un patient anesthésié. Nous avons évalué l'intérêt du renforcement de la portion distale du tube nasogastrique par une sonde Nélaton : des sondes Nélaton de calibre 8 et $10 \mathrm{CH}$ ont été introduits dans des tubes nasogastriques de calibre 16 et $18 \mathrm{CH}$ respectivement, par le premier orifice proximal et jusqu'à l'extrémité. Les patients anesthésiés ont été répartis de manière aléatoire entre le groupe témoin et le groupe de la sonde Nélaton. On a inséré le tube nasogastrique à une profondeur correspondant à la longueur de la sonde, puis cette dernière a été retirée et on a continué à enfoncer le tube pour atteindre l'estomac. Quatre-vingts patients (40 dans chaque groupe) ont participé à l'étude. Le taux de succès de l'insertion du tube nasogastrique était de $90 \%$ dans le groupe Nélaton et de $57 \%$ dans le groupe témoin $(P=$ 0,001). La durée moyenne de l'insertion était de 80 secondes (ET 43) dans le groupe à l'étude et de 92 secondes (ET 35) dans le groupe témoin. 


\section{Introduction}

It is sometimes difficult to insert a nasogastric tube in an anaesthetized and comatose patient. The success rate of nasogastric tube insertion without using any additional manoeuvre in intubated patients has been reported to be about $60 \%[1-3]$. The most common sites of resistance are the piriform sinuses and arytenoid cartilages which cause the nasogastric tube to coil around the oropharynx [1]. Many techniques have been proposed to aid nasogastric tube insertion, including forward displacement of the larynx, using a gloved finger to steer the nasogastric tube along the posterior pharyngeal wall, the water-fill method, using a laryngoscope and a Magill forceps, using a ureteric guide wire and many others [4-8]. The distal $6 \mathrm{~cm}$ of the nasogastric tube has multiple holes that are weak points promoting its bending. .We evaluated the benefit of reinforcing the distal portion of the nasogastric tube with a Nelaton catheter. The PVC Nelaton catheters used in this study were all manufactured by SUPA (SUPA Medical Device Co., Islamic Republic of Iran) with about $40 \mathrm{~cm}$ length and 8-10 French outer diameter. We inserted a Nelaton catheter with appropriate size into the nasogastric tube through the first proximal hole up to its tip to increase success rate of nasogastric tube insertion without increasing the complication.

\section{Methods}

This randomized clinical trial study was performed at Vali-e-Asr Hospital, Zanjan Medical University after obtaining approval from the ethics committee of the University and written consent from the patients. Patients with American Society of Anesthesiologists (ASA) physical status 1 and 2, aged $18-70$ years, undergoing elective general anaesthesia and requiring nasogastric tube insertion were allocated following randomization to two parallel groups according to a computer-generated randomization order. Patients with bleeding tendency, abnormal airway anatomy, those who received radiotherapy to the head and neck and those with body mass index $\geq 40 \mathrm{~kg} / \mathrm{m}^{2}$ were excluded. The criteria were designed for reducing the complication of the insertion.

The nasogastric tube insertion was performed by one anaesthesiologist who assigned patients according to the randomization schedule.

In the control group, after general anaesthesia was induced and the trachea was intubated, the patient's head was laid in neutral position, a lubricated 18 French nasogastric tube for men and 16 French nasogastric tube for women wasinserted by the anaesthesiologist. After the insertion, the oral cavity was observed in order to detect kinking of the tube. If the nasogastric tube was coiled inside the mouth, it was withdrawn and reinserted. If there was no kinking, a feeding syringe was connected to the proximal opening of the tube and air was injected while auscultating over the epigastric area to ensure its placement.

The number of attempts required for successful insertion was recorded. Successful nasogastric tube insertion was defined as when it was inserted within two attempts. After two failed attempts, other methods such as using a laryngoscope and Magill forceps were used to aid the passage of the nasogastric tube, and insertion was considered a failure.

In the intervention group, nasogastric tube insertion was done as in the control group except that the nasogastric tube was equipped with a Nelaton catheter. Well lubricated 8 French or 10 French Nelaton catheters were inserted into the 16 French and 18 French nasogastric tubes respectively through the first proximal holes of tubes up to their tips (Figure 1). The Nelaton-equipped nasogastric tube was introduced via nostril towards the oesophagus as deeply as the Nelaton catheter's length. Then the Nelaton catheter was withdrawn and nasogastric tube was inserted farther to reach the stomach. Complications such as bleeding and knotting were recorded.

The insertion time was started when the nasogastric tube was placed into the nostril and ended when the procedure was successfully completed after one or two attempts. The insertion time did not include the time for insertion of the $\mathrm{Ne}$ laton catheter into the nasogastric tube.

This study was powered by the historical data, according to which the success rate of nasogastric tube insertion without using any additional manoeuvre in intubated patients has been reported to be almost $60 \%$. The sample size was calculated based on an alpha error of 0.05 and a beta error of 0.2 , with a minimal difference of $30 \%$ in terms of the success rate of nasogastric tube insertion between the two groups. The resulting number of patients was 40 per group. Statistical analysis was performed using SPSS, version 16. The chi-squared test was used for successful insertion comparison between the groups. Age, height, weight, sex and physical status classification were analysed by independent $t$-test and Fisher exact test. The results were considered statistically significant when $P<0.05$.

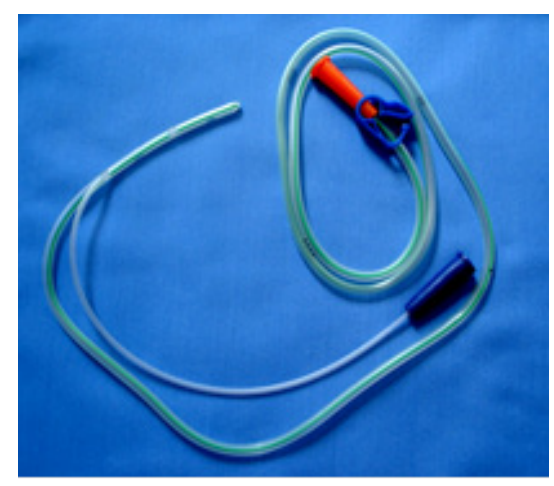

Figure 1 A Nelaton catheter inserted nasogastric tube 


\section{Results}

Eighty patients (40 in each group) were included in this study. The success rate of nasogastric tube insertion was $90 \%$ in the Nelaton group and 57\% in the control group $(P=0.001)$. The odds ratio of successful insertion in the Nelaton group to the control group was 6.6 (95\% CI: 1.9-22.2). The 2 groups were similar with respect to age, sex, height, weight and ASA physical status classification (Table 1). The mean insertion time was 80 seconds (SD 43 seconds) in the Nelaton group and 92 (SD 35) seconds in the control group. There was no statistical difference in the insertion time between the two groups. There was no statistical difference in bleeding by nasogastric tube insertion between the two groups either (Table 1). We observed no instance of nasogastric tube knotting of the nasogastric tube in either of the groups.

\section{Discussion}

Insertion of a nasogastric tube in an anaesthetized patient can be difficult and traumatic due to the inability of the patient to swallow and collapsed upper oesophageal sphincter [9]. The risk of complications increases with the number of insertion attempts. Repeated attempts at nasogastric tube insertion may injure the nasal mucosa and pharynx and cause nasal bleeding. Failure of insertion can be very frustrating and time-consuming. Therefore, it is an important clinical issue to be able to insert a nasogastric tube using a non-traumatic, safe and simple method. Various techniques of nasogastric tube insertion have been described emphasizing the fact as yet there is no simple, safe and foolproof method. Forward displacement of the larynx, using a gloved finger to steer the nasogastric tube along the posterior pharyngeal wall, and using a laryngoscope and Magill forceps are all effective

\begin{tabular}{|c|c|c|c|}
\hline \multicolumn{4}{|c|}{$\begin{array}{l}\text { Table } 1 \text { Comparison of patient characteristics and effect of Nelaton-equipped } \\
\text { nasogastric tube in the study groups }\end{array}$} \\
\hline Variable & $\begin{array}{l}\text { Control group } \\
\qquad(n=40)\end{array}$ & $\begin{array}{l}\text { Nelaton group } \\
\qquad(n=40)\end{array}$ & $P$-value \\
\hline Age [mean (SD)] (years) & $52(9)$ & $51(8)$ & 0.7 \\
\hline Sex $[$ no. $(\%)]$ & & & 0.6 \\
\hline Male & $11(27.5)$ & $13(32.5)$ & \\
\hline Female & $29(72.5)$ & $27(67.5)$ & \\
\hline Height [mean $(S D)](\mathrm{cm})$ & $164(18)$ & $163(18)$ & 0.8 \\
\hline Weight [mean (SD)] (kg) & $70(19)$ & $70(16)$ & - \\
\hline ASA status [no. (\%)] & & & 0.4 \\
\hline ASA class 1 & $35(87.5)$ & $32(80)$ & \\
\hline ASA class 2 & $5(12.5)$ & $8(20)$ & \\
\hline \multicolumn{4}{|l|}{$\begin{array}{l}\text { Effect of Nelaton-equipped } \\
\text { nasogastric tube }\end{array}$} \\
\hline $\begin{array}{l}\text { Successful insertion [no. } \\
(\%)]\end{array}$ & $23(57.5)$ & $36(90.0)$ & 0.001 \\
\hline Bleeding [no. (\%)] & $3(7.5)$ & $5(12.5)$ & 0.7 \\
\hline Knotting [no. (\%)] & 0 & 0 & - \\
\hline $\begin{array}{l}\text { Insertion time [mean (SD)] } \\
\text { (seconds) }\end{array}$ & $92(35)$ & $80(43)$ & 0.2 \\
\hline
\end{tabular}

$A S A=$ American Society of Anesthesiologists; $S D=$ standard deviation.

methods, but require someone with sufficient knowledge of the technique and practical experience. Nelaton-equipped nasogastric tube increased the success rate of nasogastric tube insertion in anaesthetized patients by almost $90 \%$. This method can be as effective as the ureteric guide wire method, whereas Nelaton catheters are readily available in any operating room, and the hazard of trauma is low. The time needed for insertion of a Nelaton catheter into a nasogastric tube is very short, taking only a few minutes.

The distal $6 \mathrm{~cm}$ of the nasogastric tube has multiple holes making that section less firm than the rest of the tube. Once the nasogastric tube touches oral structures, bending at these weak points promotes bending of the nasogastric tube. It is important to strengthen these parts of the nasogastric tube to prevent coiling of the tube in the oropharynx [10]. A Nelaton-equipped nasogastric tube makes the tube more rigid in the distal part. As a result, the nasogastric tube coils less in the oropharynx when reaching resistance, and impaction into piriform sinuses and arytenoids is signalled by obvious resistance.

Although the Nelaton-equipped nasogastric tube method did not achieve a $100 \%$ success rate, it is simple, safe, fast, non-traumatic and non-stressful. It can be easily applied in current clinical settings without any especial equipment. There are no limitations for applying this new method except that if a large size Nelaton catheter is inserted into the nasogastric tube, it may be withdrawn when the Nelaton is withdrawn, too. We suggest that the Nelaton-equipped method is possible when the patient's head is in flexion position and can increase the success rate of the method [2].

\section{Acknowledgements}

The authors would like to thank the surgeons who kindly took the time to complete the survey and the research council of Zanjan Medical University for approval of the survey.

Competing interests: None declared. 


\section{References}

1. Ozer S, BenumofJL. Oro- and nasogastric tube passage in intubated patients: fiberoptic description of where they go at the laryngeal level and how to make them enter the esophagus. Anesthesiology, 1999, 91:137-143.

2. Mahajan R, Gupta R. Role of neck flexion in facilitating nasogastric tube insertion. Anesthesiology, 2005, 103:446-447.

3. Bong CL, Macachor JD, Hwang NC. Insertion of the nasogastric tube made easy. Anesthesiology, 2004, 101:266

4. Perel A, Yaari Y, Pizov R. Forward displacement of the larynx for nasogastric tube insertion in intubated patients. Critical Care Medicine, 1985, 13:204-205.

5. Mahajan R, Gupta R. Another method to assist nasogastric tube insertion. Canadian Journal of Anaesthesia, 2005, 52:652-653.
6. Hung CW, Lee WH. A novel method to assist nasogastric tube insertion. Emergency Medicine Journal, 2008, 25:23-25.

7. Boyes RJ, Kruse JA. Nasogastric and nasoentric intubation. Critical Care Clinics, 1992, 8:862-878.

8. Mahajan R, Gupta R, Sharma A. Insertion of a nasogastric tube using a modified ureteric guide wire. Journal of Clinical Anesthesia, 2009, 21:387-388.

9. Gupta D et al. Inflation with air via a face piece for facilitating insertion of a nasogastric tube: a prospective, randomised, double-blind study. Anaesthesia, 2007, 62:127-130.

10. Chun $\mathrm{DH}$ et al. A randomized clinical trial of frozen versus standard nasogastric tube placement. World Journal of Surgery, 2009, 33:1789-1792. 